\section{Case Reports in Ophthalmology}

Case Rep Ophthalmol 2018;9:30-34

\title{
Phthirus pubis Infestation of the Eyelids Presenting as Chronic Blepharoconjunctivitis in a 6-Year-Old Girl: A Case Report
}

\author{
Viola Andin Dohvoma ${ }^{a}$ Steve Robert Ebana Mvogo ${ }^{a}$ \\ Paul Jean Adrien Atangana ${ }^{b}$ Pamela Nyasse $^{a} \quad$ Emilienne Epee $^{a}$ \\ Côme Ebana Mvogo ${ }^{a}$ \\ ${ }^{a}$ Faculty of Medicine and Biomedical Sciences, University of Yaoundé I, \\ Yaoundé, Cameroon; ${ }^{b}$ Faculty of Medicine and Pharmaceutical Sciences, University of \\ Douala, Douala, Cameroon
}

\section{Keywords}

Blepharoconjunctivitis · Phthirus pubis · Phthiriasis palpebrarum

\begin{abstract}
Purpose: To report the case of Phthirus pubis infestation of the eyelashes presenting as chronic blepharoconjunctivitis. Case Report: A 6-year-old girl presented with a 2-month history of blepharoconjunctivitis unresponsive to topical antibiotics in the left eye. Slit-lamp examination revealed the presence of nits and adult parasites on the eyelashes. Parasitological examination confirmed adult forms and nits of Phthirus pubis. There was no evidence of infestation elsewhere. Outcome was favourable with mechanical removal and application of petroleum jelly. Conclusion: Careful slit-lamp examination of the eyelashes should be done in all patients presenting with ocular irritation symptoms.

(C) 2018 The Author(s)




\section{Case Reports in Ophthalmology}

\section{Introduction}

Phthirus pubis (pubic or crab lice) is a species of human lice which infests predominantly the genital hair. Pubic lice infestation of the eyelid, known as phthiriasis palpebrarum is a relatively uncommon condition $[1,2]$.

Pubic lice are spread in adults and adolescents through sexual contact. They are transported to the lashes with the hands. In children, spread occurs by close contact, sleeping in the same bed with infested parents, or sexual maltreatment [3].

Infestation of the eyelashes may present as blepharitis. Associated conjunctivitis may result from hypersensitivity to the parasite. Misdiagnosis as allergic blepharoconjunctivitis is possible [4], hence the need for careful, high-magnification slit-lamp examination in patients with blepharitis with or without associated conjunctivitis.

We report the case of an isolated palpebral involvement presenting as blepharoconjunctivitis in a 6-year-old girl.

\section{Case Presentation}

A 6-year-old girl presented with complaints of red itchy left eye for 2 months, which was associated with mild swelling of the eyelids. These symptoms were unresponsive to topical antibiotics started 2 weeks before consultation. Previous ocular and medical histories were unremarkable. Visual acuity was 1.0 in both eyes. Ocular motility and pupillary examinations were normal. Eyelid examination was remarkable for swollen lid margins and blood-stained thickened discharge on the eyelid margins of the left eye. High-magnification slit-lamp examination of the eyelids revealed the presence of tiny translucent oval nits at the base of the eyelashes (Fig. 1) and greyish crab-like insects which clung to the eyelashes (Fig. 2). There was moderate conjunctival injection of the left eye. The right eye was normal. Fundus examination was normal in both eyes.

A total of 19 lice and 30 nits were mechanically removed using fine forceps from the upper eyelid, while 5 lice and 5 nits were removed from the lower eyelid. When the louse was firmly grasping the root of the eyelash, the lash was epilated. Some adults and nits were sent for parasitological examination. They were confirmed to be adults and nits of Phthirus pubis.

Twice-daily application of petroleum jelly to the eyelashes for 10 days was prescribed. Tobramycine and dexamethasone eye drops t.i.d. for 10 days was prescribed to treat the associated conjunctival injection. Disinfection of clothes and beddings with heat of $50^{\circ} \mathrm{C}$ for 30 min was recommended. Ophthalmic examination of family members was unrevealing. Her parents denied having Phthirus pubis infection of the axillary, pubic, or body hair. Social history did not reveal a risk for child abuse. Patient education was done on the transmission and methods to prevent transmission. A request for a dermatological examination for the parents was made. Slit-lamp examination was performed 1 week and 2 weeks later; no louse or nit was seen. All signs and symptoms had resolved. The family was lost to follow-up.

\section{Discussion}

Phthirus pubis infestation of the eyelids is commonly misdiagnosed [4], as symptoms may be confused with other causes of blepharoconjunctivitis. This is due to its infrequency and the difficulties in recognition without performing high-magnification biomicroscopy, 
Case Reports in
Ophthalmology

Case Rep Ophthalmol 2018;9:30-34

DOI: $10.1159 / 000485738$

(c) 2018 The Author(s). Published by S. Karger AG, Basel www.karger.com/cop

Dohvoma et al.: Phthirus pubis Infestation of the Eyelids Presenting as Chronic Blepharoconjunctivitis in a 6-Year-Old Girl: A Case Report

owing to the transparent structure of the lice and its localization in the roots of the eyelashes [5]. Our patient presented only when she showed no response to topical antibiotics.

Phthiriasis palpebrarum in adults is usually associated with pubic hair infestation [6]. In children, it is usually isolated as in this case because of the lack of terminal hairs on most of their body regions. Associated scalp hair infestation has been reported in children [4].

The simplest technique for the treatment of eyelid lice is direct removal of the lice and nits with fine forceps. Alternative and/or complementary treatments include petroleum jelly [6], tea tree oil [7], 1\% permethrin shampoo [6], 1\% mercuric oxide ointment [8], 20\% fluorescein [9], and 1\% malathion shampoo [10]. Given the ocular toxicity concerns and the unavailability of these chemical treatments in our setting, we opted for mechanical removal and the use of petroleum jelly in this case. Petroleum jelly applied to the eyelashes appears to be safe as this has been used by other authors [5, 6]. It does not kill the nits but smothers the lice. This breaks the life cycle as no new eggs will be laid and nymphs hatched from existing nits will be smothered. Physical treatment including cryotherapy [11] and argon laser [12] has also been reported.

Phthirus pubis is usually transmitted by sexual contact. Infestation of the eyelid is usually by hand from the pubic or axillary area. Eyelash contamination in children is secondary to contact with an adult carrier of pubic phthiriasis. The transmission can be done following sexual maltreatments or by the means of infected clothing or bed linen [3]. Affected children must be searched for sexual abuse $[1,13]$. The source of contamination was not detected in this case, given that the ophthalmic examinations of family members were unremarkable and the parents did not report for dermatologic examination. Other authors have equally reported difficulties in identifying the source of contamination in children [14, 15]. The risk of reinfestation in this child is present, given that the source of contamination was not identified. Detection of the source of contamination and treatment are necessary for the prevention of reinfestation.

\section{Conclusion}

Phthirus pubis infestation of the eyelids is commonly misdiagnosed as bacterial, viral, or allergic blepharoconjunctivitis. Easy diagnosis can be made by careful slit-lamp examination of the eyelashes and eyelid margins. Mechanical removal of the lice and nits coupled with the application of petroleum jelly is a simple, cheap, safe, and effective treatment.

\section{Statement of Ethics}

Full verbal and written consent has been obtained from the parents of the patient for submission of the manuscript for publication.

\section{Disclosure Statement}

The authors declare no conflict of interest. 


\section{Case Reports in Ophthalmology}

\section{References}

-1 López García JS, García Lozano I, Martínez Garchitorena J: Phthiriasis palpebrarum: diagnosis and treatment (in Spanish). Arch Soc Esp Oftalmol 2003;78:365-374.

-2 Anane S, Malek I, Kamoun R, Chtourou O: Phthiriasis palpebrarum: diagnosis and treatment. J Fr Ophtalmol 2013;36:815-819.

-3 Charfi F, Ben Zina Z, Maazoun M, Kharrat W, Sellami D, Makni F, Ayadi A, FekiJ: Phthiriasis pubis palpebrarum in children. Diagnosis and treatment (in French). J Fr Ophtalmol 2005;28:765-768.

-4 Yi JW, Li L, Luo DW: Phthiriasis palpebrarum misdiagnosed as allergic blepharoconjunctivitis in a 6year-old girl. Niger J Clin Pract 2014;17:537-539.

-5 Baskan C, Duman R, Balci M, Ozdogan S: A rare cause of blepharoconjunctivitis: phthiriasis palpebrarum. Niger J Clin Pract 2014;17:817.

-6 Karabela Y, Yardimci G, Yildirim I, Atalay E, Karabela SN: Treatment of phthiriasis palpebrarum and crab louse: petrolatum jelly and 1\% permethrin shampoo. Case Rep Med 2015;2015:287906.

7 Park IK, Koo H, Chun YS: A Case of phthiriasis palpebrarum treated with tea tree oil in a child. J Korean Ophthalmol Soc 2011;52:1222.

8 Ashkenazi I, Desatnik HR, Abraham FA: Yellow mercuric oxide: a treatment of choice for phthiriasis palpebrarum. Br J Ophthalmol 1991;75:356-358.

-9 Mathews M, D’Souza P, Mehta DK: A new treatment of pthiriasis palpebrarum. Ann Ophthalmol 1982;14:439-441.

10 Rundle PA, Hughes DS: Phthirus pubis infestation of the eyelids. Br J Ophthalmol 1993;77:815-816.

11 Awan KJ: Cryotherapy in phthiriasis palpebrarum. Am J Ophthalmol 1977;83:906-907.

12 Awan KJ: Argon laser phototherapy of phthiriasis palpebrarum. Ophthalmic Surg 1986;17:813-814

13 Ryan MF: Phthiriasis palpebrarum infection: a concern for child abuse. J Emerg Med 2014;46:e159e162.

-14 Ikeda N, Nomoto H, Hayasaka S, Nagaki Y: Phthirus pubis infestation of the eyelashes and scalp hairs in a girl. Pediatr Dermatol 2003;20:356-357.

$\checkmark 15$ Schenone H: Eyelids infestation by Phthirus pubis in a boy (in Spanish). Bol Chil Parasitol 2000;55:2526.
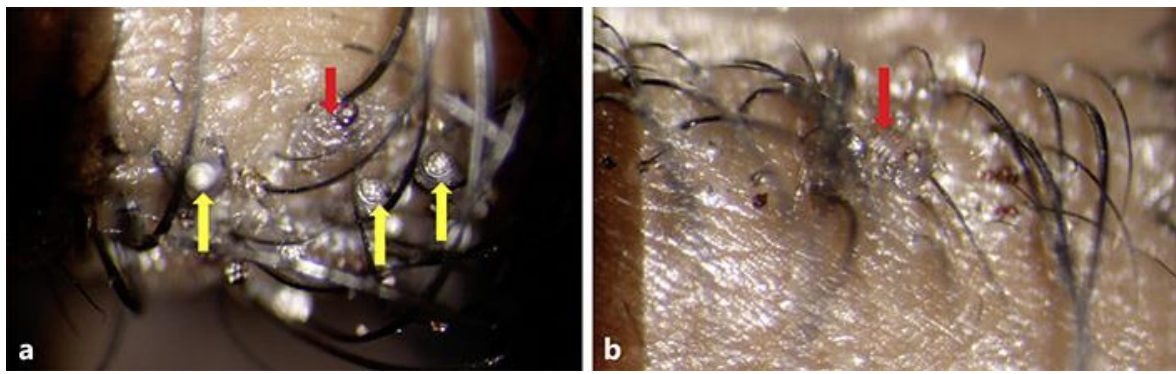

Fig. 1. Slit-lamp photographs of upper eyelid (a) and lower eyelid (b) showing adult lice (red arrows) and operculated oval nits (yellow arrows). 
Case Reports in
Ophthalmology

Case Rep Ophthalmol 2018;9:30-34

DOI: $10.1159 / 000485738$

(C) 2018 The Author(s). Published by S. Karger AG, Basel www.karger.com/cop

Dohvoma et al:: Phthirus pubis Infestation of the Eyelids Presenting as Chronic Blepharoconjunctivitis in a 6-Year-Old Girl: A Case Report
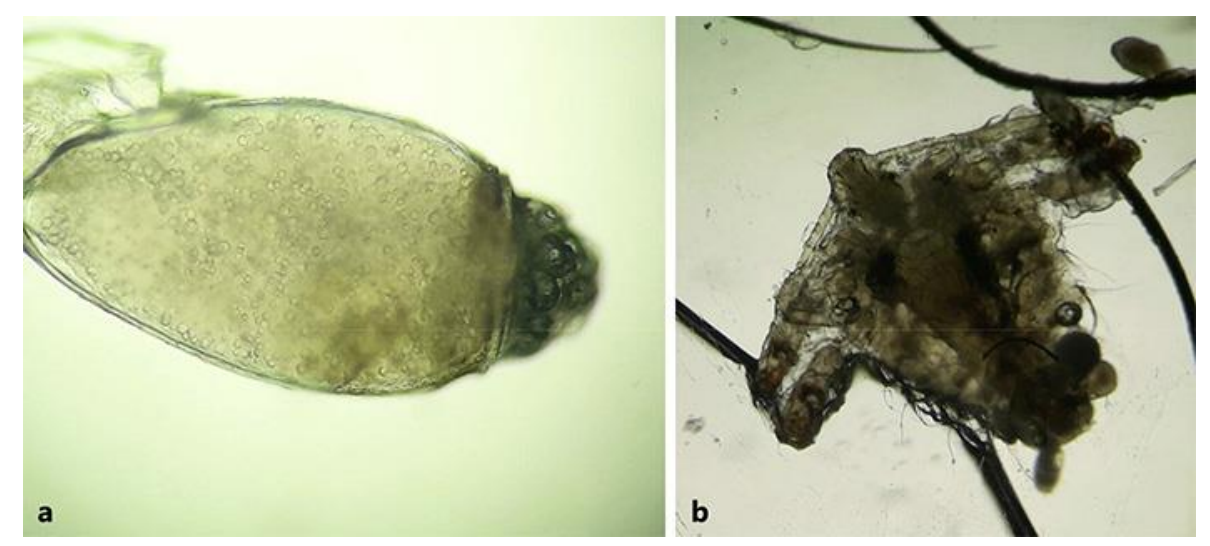

Fig. 2. Unstained nit (a) and adult parasite with claws clung to eyelashes (b) seen at magnification $\times 40$ under light microscope. 